\title{
SCHOPENHAUER EN AZORÍN. LA "NECESIDAD DE UNA METAFÍSICA"
}

\author{
Miguel Ángel LOZANO MARCO \\ Universidad de Alicante
}

Sabemos que la lectura de ciertos libros de Schopenhauer realizada por el joven J. Martínez Ruiz supuso una experiencia decisiva en la formación de su obra litcraria, especialmente desde el primer año de este siglo (las alusiones a textos del filósofo hechas con anterioridad a 1901 son irrelevantes) ${ }^{1}$, de tal modo que resulta sorprendente que la atención crítica a tal influencia no haya sido la adecuada a su importancia. Se suele hacer hincapié sobre la temática del pesimismo, o sobre la actitud de radical subjetivismo derivada de ese leitmotiv de La voluntad: "La sensación crea la conciencia; la conciencia crea el mundo. No hay más realidad que la imagen ni más vida que la conciencia" (1968, pág.74). Intento, en las páginas que siguen, indagar sobre un asunto menos tratado: la esencial aportación del filósofo alemán en la fundamentación de todo un arte, a partir del criterio azoriniano de la necesidad de una metafísica que sirva de base a una estética ${ }^{2}$; porque precisamente uno de los principales problemas con que suele encontrarse el estudioso de la obra de Azorín es el de la definición de su estética: la caracterización de esa "nueva belleza", el "nuevo arte" que proclama el escritor de manera reiterada en los primeros años del siglo XX, así como el de la situación que tal arte ocupa en la historia literaria. Y no es que carezcamos de trabajos críticos sobre tal problema: Manuel Granell, autor de uno de los más concienzudos libros escritos sobre el autor de Castilla --el que precisamente lleva como título Estética de Azorín (1949)—llegó

1 La primera cita textual que encontramos pertenece a Soledades (1898); se trata de un aforismo de Parerga y Paralipomena, de carácter anecdótico, que nada aporta al pensamiento ni a la estética del escritor.

2 Es preciso destacar en este lugar el fundamental estudio de E. Inman Fox "Azorín y la nueva manera de mirar las cosas" (1985), del que, en cierto modo, este trabajo viene a ser un complemento. 
a una definición para la etapa comúnmente considerada como la del Azorín arquetípico (1902-1925) que ha sido aceptada de manera casi unánime (no sucede lo mismo con los conceptos empleados para caracterizar el arte de las etapas posteriores a 1925). Según Granell, la estética de Azorín entre 1902 y 1925 no es otra que la "impresionista" (pág.191), y el texto más representativo —el que emplea de manera reiterada como modelo y ejemplo— sería $L a$ voluntad. Es un arte - en opinión del estudioso - fundamentado en la sensación: el escritor se sitúa ante una realidad "fugitiva, heraclitana" en la que las cosas son "vistas por fuera [...], centradas en la sensación, en el plano sensorial de la vista, del olfato, del oido..." (pág. 140) La fórmula impresionista "puede explicar ese aire inconexo característico en todas sus descipciones y vivencias de la realidad, en la misma construcción de sus libros, y hasta en su típico insinuar"(pág.189).

Sucede que esa calificación de "impresionista" nos parece más que insuficiente: imposibilita la comprensión del sentido del arte azoriniano más representativo; y en su libro, Granell cae en contradicciones graves, como veremos. Por lo pronto, recordemos que el escritor está muy interesado, a comienzos de 1905 y a propósito de su nuevo libro, Los pueblos, en llamar la atención sobre esa nueva belleza de lo vulgar e insignificante que muestra, al ensamblar armónicamente sucesos minúsculos, la "fuerza misteriosa del Universo" ". Poco tiene que ver todo ello con el impresionismo, si no es en el punto de partida, pues el escritor levantino ni se atiene puramente a las sensaciones, ni se detiene en lo fugaz de su condición -en el momento pasajero en que se producen-, ya que esa "fuerza misteriosa" que se advierte como fondo y sustancia de todo ni es fugaz ni lo puede ser.

Si una idea aparece como constante en la creación de Azorín, desde antes de que firmara con este seudónimo su primer libro hasta su última publicación, "Condensaciones de tiempo"( $A B C$, 4-II-65), es la evidencia del misterio que habita en la realidad. En Los pueblos pretende intuir "la fuerza misteriosa del Universo", y en Capricho afirma el "autor": "El gran misterio, queridos amigos, es el de la realidad que nos circunda y de la que formamos parte"(Azorín 1943, pág. 148). Un par de años antes, en el prólogo que añade a su recreación de El licenciado Vidriera anotó la misma idea: "El gran misterio está ínsito en la realidad misma que nos circuye"(1941, pág. 15). En Memorias inmemoriales, libro desde donde lanza con suficiente distancia - 1946- una penetrante mirada sobre su obra, encontramos diversos pasajes significativos; dos de ellos hemos de utilizar. En el capítulo "En la noche estrellada" reflexiona sobre el valor de las sensaciones como fundamento de su arte y de su visión del mundo; las sensaciones son "a modo de puntos fúlgidos en una vida: lucecitas que, cuando todo en nuestro torno se ha oscurecido, brillan y nos hablan, desde el remoto pretérito, de muchas cosas"(Azorín

3 "Confesión de un autor", España, 6-II-1905 (en 1975, pág. 750). Es uno de los textos esenciales para entender la estética del escritor. 
1969, pág. 1245). No son, pues, pasajeras, ni son instantáneas que fijan un momento de la realidad en perpetuo cambio, sino que evocan -o afirman - permanencias: "de las sensaciones saltamos [...] a lo que no puede expresarse, a lo Infinito"(1969, pág. 1246).

En el capítulo "Su estética" (Azorín 1969, pág. 1192) no defrauda las espectativas ofrecidas con un título tan directo: encontramos aquí, poéticamente expresada, su mejor definición en el modo de fundamentar los conceptos en su propia biografía. En primer lugar, alude a la práctica de la evocación. En la mente del escritor había "como dos espejos: en uno se reflejaba la ciudad nativa y en el otro la ciudad electiva". Cada una de ellas correspondía a una sensibilidad; y las dos se complementaban. Esos lugares predisponían, al evocarlos, a un estado de ánimo y a la experiencia de unas ciertas sensaciones; de manera que estos estímulos responden a la evidencia del mundo interior, traduciendo "una realidad intrínseca": "al encontrarse, imaginativamente, en la ciudad electiva, se entregaba X a un acendramiento de las antiguas sensaciones". En segundo lugar, explica con referencias biográficas la relación entre la realidad y el misterio. Recuerda cómo, en los años de su bachillerato en el colegio de los escolapios, salía de paseo por la vega los jueves y domingos, y se entretenía cogiendo insectos que luego, en el laboratorio, clasificaba y ordenaba. El colegio estaba formado por dos edificios: uno moderno adosado a otro antiguo, cuyo acceso estaba vedado a los estudiantes; había allí escaleras en penumbra, cámaras solitarias, y las ventanas, en lugar de cristales, tenían finas y rojizas láminas de alabastrina que difundían una extraña luz. Allí estaba el misterio que le atraía, aventurándose alguna vez en la exploración de esos ámbitos: "Y el misterio es elemento del arte". Así puede resumir su estética enlazando las dos experiencias: "A la paciente observación que requiere la entomología, asocia X el misterio inexcrutable. Toda su estética se halla compuesta de esos dos factores"(1969, pág. 1193). Evocación de sensaciones —o acendramiento de sensaciones que se producen a partir de una evocación-, observación minuciosa y atención al misterio, son los elementos fundamentales sobre los que edifica su creación; a los que hay que añadir después el estímulo fundamental: el que procede de la actividad lectora.

Esta dedicación atenta a percibir el misterio de lo que nos rodea a partir de los datos que proporcionan los sentidos, a partir de la atención a lo concreto, a lo vulgar y cotidiano, que es referencia reiterada en cualquier texto que trate sobre la actitud del escritor, carece por lo general de adecuada indagación en el terreno de la estética. Por eso llama la atención que Manuel Granell, después de manejar suficientes datos y de exponer criterios que situarían al escritor levantino en el simbolismo, concluya calificando su primera y muy dilatada época, 1902-1925, como "impresionista". El impresionismo - el predominio del momento sobre la duración; la atención a las sensaciones fugaces-que arranca del naturalismo como una consecuencia de la atención a la realidad fenoménica y a su manera de ser 
percibida, se convierte también en sostén de la reacción idealista del simbolismo cuando el poeta, por debajo de la visión fragmentaria y pasajera de la impresión, intuya la dimensión espiritual de las cosas, los misteriosos nexos que las relacionan, e intente reconstruir la unidad del mundo, perdida tras la bancarrota de la metafísica tradicional, (Hauser 1971, pág. 213). Granell subraya adecuadamente el hecho de que el arte de Azorín tiene su base en la sensación, y cómo desde aquí consigue "penetrar en la zona oscura del misterio"; alude al salto desde la sensación al infinito, al buceo en la dimensión espiritual que alumbra con su prosa, y al "hilo misterioso" que pone en contacto a las cosas con su sensibilidad; pero, sorprendentemente, resume su primera época con una fórmula que contradice todo lo anterior: "Azorín mira el mundo - las cosas y los hombres- desde fuera"; y desarrolla la idea: "El autor se sitúa muy próximo a lo real, en visión ccrcana, de miniaturista. Ve desde fuera las cosas, testificando la presencia de las mismas"(Granell, pág. 135). Un poco más adelante escribe, sacando consecuencias: "Resumamos. En primera instancia, las cosas de este mundo novelístico son las que el hombre halla en la vida vulgar [...]. Vistas por fuera, no pensadas ni analizadas; pero centradas en la sensación, en el plano sensorial de la vista, del olfato del oído..." (pág. 140). La definición de la estética de Azorín es, de este modo, insuficiente, y casi parece reducirse a una lectura superficial de La voluntad. Pero es más sorprendente la propia contradicción en la que cae, convirtiendo en grave defecto la consecuencia directa de su criterio: "Se puede ser idealista subjetivo en filosofía, pongamos por caso, y realista en arte. No es otra cosa la posición de Azorín, tal como aparece en La voluntad. Cita a Schopenhauer y a Berkeley; escribe que 'no hay más realidad que la imaginada [sic], ni más vida que la conciencia', y asegura que 'la imagen lo es todo'. Y, no obstante, cuando olvida la metafísica y medita en su arte, no puede menos de entusiasmarse con Juan Ruiz y menospreciar a Rojas. Es la fruición de las cosas lo que le mueve"(págs. 129-130). Su conclusión es que existe en Martínez Ruiz una separación, y oposición, entre el filósofo y el artista; y que es el artista el que predomina al observar "con cl máximo escrúpulo la realidad", a la manera de Zola. Sus conclusiones han tenido dilatada descendencia, como apuntábamos antes, y han logrado impedir el entendimiento de un arte con sólido fundamento metafísico, sin contradicción alguna entre la concepción filosófica y la praxis creativa. Si a esa idea de "miniaturista" - resucitada recientemente por Mario Vargas Llosa (1995 y 1996)- de escritor atento a las cosas, unimos los criterios estéticos derivados del concepto ideológico de "generación del 98", podemos ir entendiendo la distorsión con que ha venido siendo enjuiciada la producción literaria más representativa de Azorín.

La visión era más nítida en los primeros años del siglo, y un recorrido por las páginas de Helios, la revista que, al parecer, "empezó con el propósito de propagar el simbolismo francés en sus páginas" (O'Riordan 1973, pág. 129) nos muestra cómo los poetas modernistas entendieron la cercanía entre la estética de Martínez Ruiz y su propio arte. En esa misma revista, doña Emilia Pardo Bazán, al reflexio- 
nar sobre la nueva generación de novelistas, sitúa a Martínez Ruiz "de lleno en la corriente modernista", lo califica de "bohemio místico", alude a su pesimismo, identifica las "influencias mentales del Norte" que operan sobre la tendencia en les nombres de Nietzsche, Schopenhauer y Maeterlinck (1904, pág. 258). Gómez de Baquero abunda en la visión simbolista, entendida según los criterios expuestos por los poetas de Helios, cuando afirma que Martínez Ruiz "tiene ojos para lo sensible y penetración psicológica para lo espiritual", después de asumir dentro de sus criterios la metafísica de Schopenhauer (1905, pág. 96). Un año después, en 1906, Andrés González Blanco resume todas estas apreciaciones — la sensación, el hondo misterio de las cosas más sencillas, el vitalismo, la práctica de la evocación frente a la descripción...- para conducirlas hacia una consideración de Los pueblos como su más perfecta realización; es "música de ensueño con letra de plasticidad" en textos de profundo calado lírico (1906, págs. 66-67).

Por aquellos días, en un artículo aparecido en Alma Española, dedicado a comentar Arias tristes, escribe Martínez Ruiz: "Ia metafísica y la poesía son hermanas"(Azorín 1904, pág. 14). Afirmación tan sucinta nos obliga a reflexionar sobre esa concepción que vincula la realidad estética con la indagación en las causas últimas, en el fundamento del mundo sensible. Y no sólo el lírico, también el crítico necesita recurrir a la filosofía para entender la creación artística; así encontramos subrayada en uno de los libros de Baudelaire, leído con atención, una frase sobre la que reflexionó el levantino: "la critique touche à chaque instant à la metaphysique"(1890, pág. 81). Pero donde de una manera rotunda y directa, sin ambages, aborda Azorín el problema que apuntamos y lo resuelve con nitidez cs en su artículo "La nueva crítica" cia. Plantea aquí "la necesidad inevitable de una metafísica que sirva de base a una estética"(1944, pág. 181), y define las condiciones de esa metafísica. El arte de Azorín se entiende perfectamente desde estos criterios y a partir de los ámbitos y referencias que desde aquí se abren.

"La nueva crítica", artículo escrito en la época en que va componiendo los textos que formarán parte de Los pueblos, y que junto con "La nueva poesía"s expresa la conciencia de una profunda renovación --llámese Modernismo o cualquier otra cosa-, comienza con un paisaje, una descripción de la naturaleza — que podría ser calificada de impresionista- y con unos conceptos semejantes a los que encontramos en "Confesión de un autor". Los conceptos son los de armonía y síntesis en los detalles observados. En la hora del atardecer, los matices y los ruidos del campo "se conciertan y funden en un todo misterioso y potente"; hay una relación entre todos los elementos: el espejeo lejano de un azarbe, el son de una esquila, el zumbido de una abeja, el beso de la luz en las laderas azules... Pero también lo construido por el

4 Publicado en España el 20-V-1904 y recogido posteriormente (Azorín 1944, págs. 179-183).

$5 \quad$ Publicado en $A B C$ el 6-VII-1905 (Azorín 1945, págs. 148-152). 
hombre forma parte de esa "síntesis suprema", y a modo de imagen emblemática el escritor selecciona un detalle que aisla para atender a otra composición más reducida pero sugerente: un muro viejo y rojizo que se levanta a espaldas de una casa cerrada, junto al que un almendro extiende su follaje. Aquella imagen —el árbol junto al muro viejo - le mueve a la contemplación; desde ahí se eleva al conocimiento: en esta armonía inefable, que ha ido creando la naturaleza, se nos manifiesta "la Idea de Platón, la Voluntad de Schopenhauer". Los detalles que ha ido observando, ensamblados armónicamente, muestran "la fuerza misteriosa del Universo", o "el alma profunda de la Naturaleza" como afirma en esta ocasión. Esa fuerza o "energía oculta" que, como decía Platón, "es, sin acabar de ser nunca", se va exteriorizando y constituye "las modalidades definitivas, eternas, de la Naturaleza y del arte". Pero no es en el platonismo donde termina Azorín; su referencia queda abiertamente declarada: "Schopenhauer, en un libro maravilloso, La voluntad en la naturaleza, ha sentado las bases de esta estética"(1944, pág. 182). Así, el conocimiento y la creación dependen de esa actitud del contemplador, de donde surgen los primeros párrafos del texto y desde donde se eleva a la intuición del "alma profunda" de lo contemplado. Se trata de un panteísmo, pero no "abstracto y apriorístico", sino fundamentado "en el estudio largo y tenaz de las ciencias naturales y en la observación minuciosa de la Naturaleza, base necesaria, imprescindible, para toda especulación estética" (1944, pág. 183). El panteísmo es un resultado de la observación atenta, dependiente de ésta, y no producto de creencias que preceden a la observación.

Desde estos criterios entendemos las consideraciones expuestas anteriormente; aquí están los datos básicos que explican tantas páginas representativas del arte de Azorín - y el texto en el que autor reflexiona sobre su obra-; pero también esos otros escritos más tardíos, como los que vinculan la observación con el misterio. Y todo ello delata el error en que se ha movido la teoría de Manuel Granell y la de quienes lo han seguido o han coincidido con él; porque la minuciosa observación del artista no entra en conflicto con la filosofía que pretende abrazar, sino que su fundamento filosófico, su metafísica, le obliga a la observación. No es, pues, "idealista subjetivo" en filosofía y "realista" en arte, y estos extremos han de ser adecuadamente aclarados.

En Sobre la voluntad en la naturaleza, publicado dieciocho años después de la aparición de El mundo como voluntad y representación, muestra Schopenhauer su satisfacción al considerar que los investigadores científicos han venido a darle la razón, puesto que trabajando cada uno en su parcela científica, y sin prevención alguna, han llegado al núcleo mismo de su metafísica. Los avances en las ciencias naturales han confirmado su sistema al haberse puesto en contacto la física con su metafísica, de igual modo que dos mineros trabajando en el seno de la tierra, y partiendo desde puntos lejanos, guiados por su juicio, llegaran a encontrarse en un lugar. Estimulado por lo que juzgaba su triunfo afirma: "El nombre a que aspira mi filosofía es al de filosofía del porvenir, de la época que no se satisfaga ya con hueca palabrería, 
frases vacías y paralelismos de juego, sino que exija a la filosofía contenido real y explicaciones serias"(Schopenhauer 1970, pág. 47). Atentos al radical subjetivismo del "mundo como representación", suelen los críticos olvidar el empeño del filósofo alemán por explicar un mundo que conoce en virtud de una observación atenta.

Como sabemos, Schopenhauer identifica la "cosa en sî" de Kant, la sustancia única y eterna, en la voluntad. Ésta es la energía que lo constituye todo, que se manifiesta en el reino mincral, en el vegetal y en el animal, y que en la forma más elevada de conciencia, el hombre, ha producido, para su servicio y fines, la cualidad de la inteligencia. No hay, pues, dos principios, voluntad e inteligencia, pues la inteligencia es de carácter secundario, relativo, y subordinado a la voluntad. Pero mediante la inteligencia el hombre conoce el mundo, se lo representa; ante ella se despliega un espectáculo diverso en el tiempo y en el espacio, espectáculo que sólo existe en el cerebro que lo recoge. Las imagenes del mundo no son la esencia última de los seres, pues no dejan de ser un "mero fenómeno cerebral"; lo "objetivo" no son las cosas, no es la realidad fenoménica, sino la existencia de ese cerebro, de esa conciencia en la que el mundo de los fenómenos se identifica (pág. 64), al tiempo que se identifica a sí misma. Este criterio es el considerado "objetivo" y "realista" por Schopenhauer (pág. 125).

El mundo como representación, toda esa variedad y diversidad de formas y seres que se extiende ante nosotros en el espacio y en el tiempo, existe - sólo en un cerebro- porque la voluntad ha necesitado de la cualidad de la inteligencia, desarrollada en el hombre (pág. 122). El mundo de la voluntad es el del perpetuo desear, y por tanto el del dolor, el egoísmo, la insatisfacción y la necesidad. Pero la inteligencia, creada por la voluntad para su servicio práctico, puede separarse del principio que la creó, actuar independientemente, entender el sentido negativo del perpetuo desear y el fraude de la individuación, y abstenerse: renunciar al deseo. Puede así el hombre contemplar desinteresadamente el mundo, y hasta recrearse en él, lo que no podría hacer si estuviera movido por afán práctico; puede así atender concretamente a las imágenes del mundo, objetivarlo, y convertirse la conciencia que así obra en sujeto de la objetivación. A tal estado de contemplación desinteresada llegan muy pocos hombres, pues lo común y usadero es atender a aquello que les interesa y comprender sólo lo que se relaciona directamente con ellos. Atender desinteresadamente, por el puro conocer, es actividad que en sus más altas manifestaciones se produce en el hombre de genio; en ellos el intelecto ha de estar separado de la voluntad: "Cuanto más eminente la cabeza, tanto más se pierde esto [el existir para ayuda de la voluntad] y de una manera tanto más puramente objetiva se representa el mundo exterior, hasta que alcanza, por fin, en el genio la perfecta objetividad, merced a la cual surgen de las cosas individuales sus ideas platónicas, por elevarse el que las comprende a puro sujeto de conocer" (pág. 129).

Azorín leyó muy atentamente este libro de Schopenhauer, medito a lo largo de su vida — como lo declara en sus Memorias inmemoriales - sobre estas ideas; 
pero también atentamente leyó y asimiló otra obra de este filósofo dedicada a indagar en el sentido y condiciones de la creación artística, su Metafisica de lo bello y Estética, que amplía las ideas sobre el arte contenidas en el anterior libro, y en $E l$ mundo como voluntad y representación. Esta Metafísica de lo bello es de importancia capital para entender la estética de Azorín y el carácter original de sus textos más representativos, y a este libro tendríamos que recurrir para analizar obras como Los pueblos o Castilla. Reitera aquí el filósofo alemán que la decisión de emanciparse, de liberarse de la voluntad para atender a los objetos del mundo sin desearlos nos hace entender que es la misma voluntad la que se objetiva en cada uno - -ya que todo lo fenoménico es manifestación de esa fuerza ciega que aspira a perpetuarse-; que nosotros somos voluntad que se conoce a sí misma, y que al conocerse se objetiva. "Sólamente así se produce, con el sujeto puro, el objeto puro, es decir, la manifestación completa de la voluntad, que aparece en el objeto percibido, que es precisamente la idea (platónica) del mismo [...]; cualquier cuadro da, no lo individual, sino la idea, lo duradero en todo cambio, sólo por el hecho de fijar para siempre el momento fugitivo y salir, por lo tanto, fuera del tiempo"(s.a., pág. 9).

El arte nos lleva a un profundo conocimiento de todo precisamente porque en un individuo se nos revela la idea de su especie, del mismo modo que una sola escena nos muestra lo que es la vida y la naturaleza del hombre(s.a., págs. 15-16). Así, la noción de idea platónica es clave en la estética de Schopenhauer, y aparece en no pocos textos de Azorín. También explica el carácter visual de su arte, puesto que la imagen elaborada por el artista está más cerca de la idea que de la realidad; en primer lugar, porque ha pasado a través de un sujeto; en segundo lugar, porque en la obra de arte se nos muestra la forma solamente, desligada de su materia; y esa imagen, pura forma, nos revela su idea: "esta desunión de la forma y la materia es propia del carácter de la obra artística, precisamente porque su objeto es llevarnos al conocimiento de una idea (platónica)"(s.a., pág. 17). Ésta es la razón por la que vamos entendiendo que en Azorín cada objeto y cada personaje no es algo único y aislado, irreductible, sino que resume y contiene una serie de identidades, es igual a otros muchos en repetición infinita, en manifestación de su idea; y no fue otro el criterio expresado por Ortega y Gasset con singular penetración: "Ningún personaje de Azorín, ninguna acción, ningún objeto tienen valor en sí mismos. Sólo cobran interés cuando percibimos que cada uno de ellos es sólo el cabo de una serie ilimitada compuesta de elementos idénticos"(1987, pág. 331).

Es la metafísica de Schopenhauer lo que explica el interés de nuestro escritor por el mundo de los objetos: la peculiar objetividad de su arte, que no consiste en producir un reflejo del mundo fenoménico, sino en suscitar una presencia de la idea de cada objeto y cada ser recreado por el escritor. También de este modo podemos entender de manera adecuada el problema del "arte y la utilidad". Desde este punto de vista, el arte es por esencia y necesidad algo radicalmente carente de utilidad: "el trabajo de la inteligencia libre, emancipada del servicio de la voluntad, 
origina la consecuencia de que sus obras no sirven para fin útil alguno" (Schopenhauer 1960, II, pág. 283). Si el artista ha de objetivar el mundo, objetivándose él también, contempla y conoce sin desear; porque al desear se situaría bajo el dominio de la voluntad, y con ello quedaría desvirtuado el arte al estar sometido al servicio de apetencias y deseos. De ahí también que los espíritus mediocres, al moverse por intereses prácticos, no aprecien ni entiendan el arte. La obra artística, pues, libera al hombre del sufrimiento y lo pone en disposición de comprender los resortes de la vida y los movimientos de la voluntad que logra ser objetivada con adecuada distancia estética.

La misma referencia platónica, y el conocimiento de la voluntad como verdadera realidad o "cosa en sî", permite aventurarnos en la comprensión del significado de ese concepto metafísico, del "alma de las cosas"; porque Azorín llega a identificar el "alma del mundo" con la voluntad. En su artículo sobre Pío Baroja de $1903^{6}$, de sorprendente comienzo, traza un panorama del grupo de escritores que había irrumpido pocos años antes - Valle-Inclán, Maeztu, Bueno, Palomero, Acebal, Navarro Ledesma, Sawa, Bobadilla, Rueda, Unamuno y Baroja- a los que diagnostica el inicio de su decadencia. Sorprende porque, aún jóvenes, han de crear todavía sus obras más representativas, pues la citadas en el texto de Martínez Ruiz son, casi todas, lo que se llama "escritos de juventud". Y no es porque estime el articulista que Unamuno sea incapaz de superar su "Nicodemo el fariseo", o Baroja su Camino de perfección por lo que "la decadencia se ha iniciado en ellos", sino porque considera que cada uno ha logrado ya su estilo, su manera particular: "Todos han creado ya su forma; lo que ha llamado Schopenhauer la voluntad, es decir, el alma del mundo, ha encarnado ya de una vez por todas, definitivamente, en una modalidad única, y sería inútil cuanto se haga por sobrepujarla o modificarla esencialmente"(1945, pág. 139). Azorín ha aprendido bien la lección del filósofo; sabe que él, como todos, es esclavo de la voluntad; pero que como artista logra liberarse de ella, se distancia, y la contempla: "la sustancia universal se ha exteriorizado a través de nosotros, artistas"(1945, 140); de esa manera ve el mundo y entiende tanto la fuerza germinadora de la naturaleza, tras la cual late el alma de todo, como la propia capacidad creadora del hombre, partícipe de esa misma alma. También subraya aquí la profunda relación -identificación más bien-entre la voluntad schopenhaueriana y la cosmovisión platónica: una de las bases del pensamiento de aquél; y ello asegura la veracidad de una visión animada del universo que fundamenta tanto el mundo clásico como el romántico, en cuyo origen —el romanticismo alemán- es esencial la concepción panteísta que se manifiesta de manera fecunda para el arte en la noción de símbolo; todo ello salvando el sentido negativo que la voluntad adquiere en el sistema del filósofo pesimista.

6 Publicado sin firma en Alma Española el 27 de diciembre con el título "La Busca", recogido en Los clasicos redivivos (1945) con el título "Pío Baroja". 
La visión de la naturaleza - y de la vida el hombre- desde criterios schopenhauerianos está en la esencia misma del arte de Azorín, y aparece de manera reiterada en capítulos y ensayos, e incluso en artículos de carácter divulgador. En su "Segundo curso abreviado de pequeña filosofía" muestra la fuerza de la voluntad en la vitalidad y capacidad de adaptación de los insectos, y la superioridad de estos minúsculos seres en ese emblema de la araña que atraviesa desdeñosa la página de un libro (1944, pág. 19). Más aún, en un artículo de $A B C$ refiere un sencillo paseo por la montaña contemplando flores e insectos, demorándose en la visión de esa vida minúscula en apariencia, para concluir con la enseñanza que se extrae de esa minuciosa observación: "Nos enseña, indudablemente [todo lo observado], que la vida es multiforme, varia, compleja; que existe una fuerza, una voluntad universal que se manifiesta en mil distintas formas y que aprovecha para exteriorizarse todos cuantos medios podemos imaginar. Nos enseña que la vida no tiene más fin que la vida. Nos enseña, finalmente, que nosotros conocemos la ley de causalidad, que es lo que constituye el enlace de los fenómenos, pero que la cosa en sí, la esencia, lo que sea esa voluntad de que hemos hablado, eso no lo podremos conocer jamás"(Azorín 1906, pág. 7). Para Azorín, la voluntad es también el misterio al que constantemente alude. Es cierto que para Schopenhauer el misterio rodea al hombre, como afirma en Sobre la voluntad en la naturaleza: "estamos sumidos en un mar de enigmas y de incomprensibilidades, y que no conocemos inmediatamente a fondo las cosas ni a nosotros mismos"(1970, pág. 163). Por ello Azorín concluye su libro Al margen de los clásicos refiriéndose al "alma de las cosas... misterio de lo que nos rodea" (1969, págs. 956-957). De esta manera el arte puede manifestar en profundidad la experiencia completa del hombre al tratar sobre la vida y su trasfondo; al mostrar el mundo y atender a su alma; al dar al mismo tiempo la forma del objeto y su misterio.

Podemos, con estas consideraciones, avanzar en la comprensión de un arte de gran coherencia en el que todo elemento encuentra su lugar y su relación en el seno de una estética compleja y de fundamentos sólidos. Nada hay gratuito ni disonante y en cada aspecto se nos revela la originalidad de su mundo; una originalidad reclamada también por Schopenhauer en el libro que, probablemente, fue el primero del filósofo alemán leído por el "pequeño fillósofo" español, Parerga y Paralipomena; alli escribe: "Es necesario, tras madura reflexión, tras meditación seria, obrar conforme al propio carácter. La originalidad es, pues, indispensable aún en la vida práctica; sin ella lo que se hace no se acuerda con lo que se es"(1889, II, pág. 117). En el mismo libro se reprueba el estilo oscuro y afectado, se demanda una expresión clara y se subraya el carácter subjetivo del estilo, que viene a ser considerado como la fisonomía del espíritu. A todo esto responden los criterios de claridad y exactitud, la valoración de lo innato y la definición del estilo que de manera repetida leemos, con variaciones sobre el tema, en distintos lugares de la escritura azoriniana. En su más original ensayo de estética, Un pueblecito: Riofrío de Ávila, podemos encontrar la más directa expresión de estas ideas, y en su definición del 
estilo acusamos el eco de las consideraciones expresadas en el citado artículo de 1903, referentes a cómo en los escritores de su ambiente y edad ha encarnado ya la voluntad en una modalidad única; de este modo puede afirmar que el estilo es la espontaneidad, surge en un impulso creador que no está en nuestra mano modificar, si no es falseándolo: "El estilo no es voluntario. El estilo es una resultante fisiológica" (1969, pág. 504). Desde el sistema filosófico de Schopenhauer entendemos el sentido de estas afirmaciones.

Una consecuencia más encontramos en sus reflexiones sobre la nueva poesía. Sabemos que Azorín siempre estuvo interesado por las novedades literarias que las sucesivas promociones -o generaciones - iban aportando, y ello desde fechas muy tempranas, desde el momento en que pudo advertir la presencia de un grupo de escritores que sucedía directamente al suyo: el grupo de los "novísimos" que sucede a los "nuevos"; grupo de poetas que han llegado a un nuevo lirismo, a "un idealismo superior", porque se sustentan "de una base de observación, de vida menuda y cotidiana" (Azorín 1911). Entre estos líricos de hondo aliento poético fundado en la observación, destaca Antonio Machado. A él dedica los párrafos fundamentales de su ensayo "El paisaje en la poesía"7 con criterios muy ajustados, pero que perfectamente pueden ser aplicados a su propio autor. El concepto fundamental es el de "objetivación": los paisajes en sus versos son "una colección de detalles" donde el lírico se objetiva. "La característica de Machado [...] es la objetivación del poeta en el paisaje que describe". Hasta ahora, viene a decir Azorín, los poetas contemplaban el paisaje y lo describían impersonalmente. "Ahora, no; paisaje y sentimiento - modalidad psicológica - son una misma cosa; el poeta se traslada al objeto descrito, y en la manera de describirlo nos da su propio espíritu"(1975, pág. 1072). El criterio de objetivación aplicado a un estado de alma tiene su origen en la metafísica que consideramos: lo que se objetiva y se contempla estéticamente -es decir, desinteresadamente - es la relación de la conciencia del escritor con la forma de los objetos presentes en el poema, de manera que en esa forma lingüística se incorpora el objeto - los nombres - y el sujeto del acto de la observación. El poeta selecciona y nombra aquello que da forma a un sentimiento, mostrando en lo que nombra un "estado de alma". Del mismo modo, los paisajes de Azorín responden a este criterio: en la apariencia de una pura observación objetiva - lo que fue considerado impresionista— está el intento de expresar algo más, de mostrar su relación con lo nombrado; es lo que sabiamente denominó Yuste la "emoción".

No es original, desde luego, la identificación de la base metafísica de Schopenhauer en el arte de Azorín; sí lo puede ser la aplicación concreta de este criterio a unos textos que no han solido verse a esta luz. El primer lugar entre los

7 Con el título "El paisaje en los versos" fue publicado en $A B C$ (2-VIII-1912); recogido al año siguiente con el título definitivo (1975, 1069-1072) 
que han aportado criterios precisos en este terreno le corresponde a César Barja, quien en 1935 vio con claridad como no es Nietzsche el que inspira al autor de Castilla, pues son "dos actitudes más bien opuestas", sino Schopenhauer; de éste procede la metafísica, "Y más que la metafísica el sentimiento azorinesco del mundo como pura representación"(1935, pág. 271). La idea aparece desarrollada suficientemente en Inman Fox (1985) e incorporada a la consideración de su grupo generacional por Pedro Cerezo Galán en un estudio altamente clarificador donde identifica la metafísica pesimista de la voluntad como aquello que constituye "el sustrato ideológico más profundo de la generación" (1993, pág. 176). De Nietzsche procedería un principio de creación, una afirmación de la voluntad de poder que alentaría un individualismo egotista, y una actitud iconoclasta. Pero el fracaso de la aspiración de la voluntad les confirma en la experiencia del nihilismo y les devuelve al pesimismo schopenhaueriano. Azorín es, desde luego, quien mejor ejemplifica los fracasos de la voluntad de poder, el carácter estéril de la rebeldía, y el ingreso en un ámbito propio en el que las imágenes que pueblan su conciencia aseguran la estabilidad de un mundo donde se transmuta en ensueño, y se convierte en lenguaje, un caudal escogido de visiones y de lecturas.

\section{OBRAS CITADAS}

AZORÍN (J. Martínez Ruiz) [1902] 1968. La voluntad, ed. de E. Inman Fox, Madrid, Castalia.

- 1904. "Los libros. Dos palabras", Alma Española, 24 de enero, págs. 13-14.

- 1906. "En la montaña", $A B C, 6$ de junio, págs. 6-7.

- 1911. "Las influencias literarias", $A B C, 13$ de julio.

- 1944. Tiempos y cosas, Zaragoza, Librería General.

- 1945. Los clásicos redivivos. Los clásicos futuros, Madrid, Espasa-Calpe.

- 1941. Tomás Rueda, Buenos Aires, Espasa-Calpe.

- 1943. Capricho, Madrid, Espasa-Calpe.

- 1969. Obras Selectas, Madrid, Biblioteca Nueva.

- 1975. Obras Completas. I, Madrid, Aguilar.

BARJA, César. 1935. "Azorín”, en Libros y autores contemporáneos, Madrid, Librería General de Victoriano Suárez, págs. 264-298.

BAUDELAIRE, Ch. 1890. Oeuvres Complètes, Paris, Alphonse Lamerre Éditeur. 
CEREZO GALÁN, Pedro. 1993. "El pensamiento filosófico" en Historia de España. Ramón Menéndez Pidal, dirigida por José María Jover Zamora, t. XXXIX, La Edad de Plata de la Cultura Española, I, Madrid, Espasa-Calpe, págs. 233-315.

FOX, E. Inman. 1985. "Azorín y la nueva manera de mirar las cosas", Actes $d u$ Premier Colloque International "José Martínez Ruiz (Azorín), Université de Pau, págs. 349-356.

- 1988. Ideología y política en las letras de fin de siglo (1898), Madrid, Espasa-Calpe.

GÓMEZ DE BAQUERO, E. 1905. Letras e Ideas, Barcelona, Imprenta de Henrich y $C^{a}$.

GONZÁleZ BLANCO, Andrés. 1906. Los Contemporáneos.I., París, Garnier.

GRANELL, Manuel. 1949. Estética de Azorín, Madrid, Biblioteca Nueva.

HAUSER, Arnold. 1971. Historia social de la literatura y el arte. III. Naturalismo e Impresionismo. Bajo el signo del cine, Madrid, Ediciones Guadarrama.

O'RIORDAN, Patricia. 1973. "Helios, revista del modernismo (1903-1904)", Abaco, 4, Madrid, Castalia, págs. 57-150.

ORTEGA Y GASSET, José [1917] 1987. “Azorín: Primores de lo vulgar”, E. Inman Fox, ed., Meditaciones sobre la literatura y el arte, Madrid, Castalia, págs. 307-349.

PARDO BAZÁN, Emilia. 1904. "La nueva generación de novelistas y cuentistas en España", Helios, n’. 12 (marzo), págs. 257-270.

SCHOPENHAUER, Arthur [1819] 1960. El mundo como voluntad y representación, Trad. de Eduardo Ovejero y Mauri, Buenos Aires, Aguilar, 3 vols.

-[1836] 1970. Sobre la voluntad en la naturaleza, trad. de Miguel de Unamuno, Madrid, Alianza Editorial.

- [1851] 1889 Parerga y Paralipomena, Madrid, Biblioteca Económica Filosófica, 2 vols.

- (s.a.) Metafísica de lo bello y Estética, Madrid, B. Rodríguez Serra, Editor.

VARGAS LLOSA, Mario. 1975. "El miniaturista" en Azorín, Páginas escogidas, Alicante, Eds. Aitana, págs. 455-462.

- 1976. Las discretas ficciones de Azorin, Discurso de Ingreso en la R.A.E., Madrid, Real Academia Española. 